\title{
Optimum Power Contribution Ratio of Two Pinion Gears Engaged with Rack Rail for Monorail Driven in Forest Industry
}

\author{
Kazunori NAKAMURA ${ }^{1, \text { a }}$, Kazuya OKUBO ${ }^{2, b}$, \\ Toru FUJII ${ }^{2, \mathrm{c}}$ \\ ${ }^{1}$ Graduate student of Doshisha University, Kyoto, Japan \\ ${ }^{2}$ Department of Mechanical Engineering, Doshisha \\ Univ. \\ ${ }^{1,2}$ Miyakodani, Tatara, Kyotanabe city, Kyoto, Japan \\ e-mail: dum0547@mail4.doshisha.ac.jp, \\ bkokubo@mail.doshisha.ac.jp, \\ ctujii@mail.doshisha.ac.jp
}

\author{
Shoji UCHIDA \\ UCHIDA Industrial Co.Ltd, Kyoto, Japan \\ Higashitsuchikawa, Kuze, Kyoto city, Kyoto, Japan
}

\begin{abstract}
The purpose of this study is to find the optimum power contribution ratio defined as the ratio of traction force applied onto rack rail by front pinion gear and rear pinion gear of monorail used in this study.

At first, relation between loading weight and applied stress was investigated when loading weight $M_{b}$ on the bogie was changed. Power contribution ratio was estimated using this relationship. The effect of the condition of power contribution ratio on the normal stress applied onto the rack tooth was simulated using obtained relations. The optimum power contribution ratio of front pinion gear was defined as an effective designing parameter to reduce the stress applied onto the rack tooth. A reduction ratio determined with the ratio of maximum compression stress on the tooth considering power contribution ratio to that of conventional case was estimated when the optimum power contribution ratio was considered.

It was found that most of traction force was sheared by the front pinion gear not depending on magnitude of traction force, because the revolutions of the front and rear pinion gears was directly constraint due to the link system of the connection in the gear box of current monorail. The optimum power contribution ratio was $\alpha=0.53$ when the representative location of the contacting forces on front pinion gear was $h 1=5.6 \mathrm{~mm}$ measured from the root of tooth, and that on rear pinion gear was $h 2=7.0 \mathrm{~mm}$, respectively. The maximum reduction with $47 \%$ in observed compression stress was obtained by determining optimum power contribution ratio under the condition at $5.54 \mathrm{kN}$ of total traction force.
\end{abstract}

Keywords- Component; FEM; Monorail; Rack and Pinion gear; Backlash; Pitching angle; Power Contribution Ratio; Compression stress.

\section{INTRODUCTION}

Forest soil is an important component of the natural environment [1]. To carry soil, garbage, workers, heavy equipment, landslide to or from the mountain and the place of not leveled steep slope, using monorail for forest industry is one of the best ways (Fig.1). Application of this monorail can reduce the time for construction than that by other ways and improves the work efficiency, because monorail has excellent ability to carry a lot of stuffs loaded for operations. Although monorail has many advantages as mentioned above, some problems are often shown in using at which rack teeth were irregularly worn much rapidly than expected as shown in Fig.2 due to carrying over capacity loading weight on bogie. In such case, serious wear of the rack teeth is initiated by complicated mechanism, because two pinion gears are synchronously rotated by the power motor.

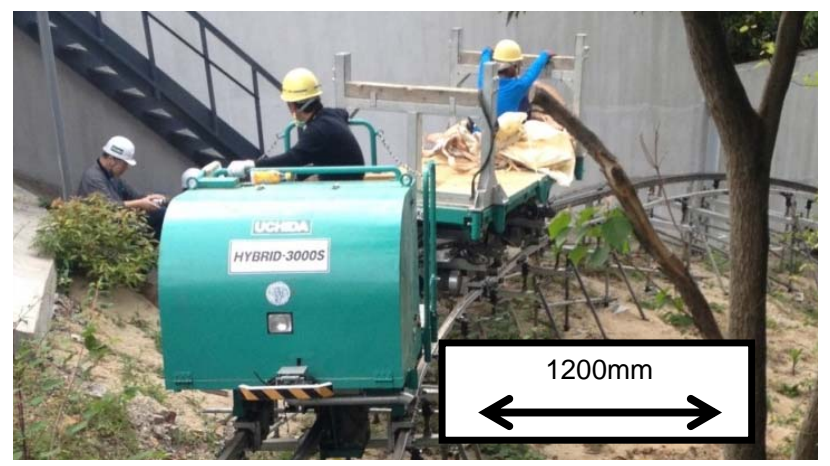

Fig.1 Monorail for forest industry.

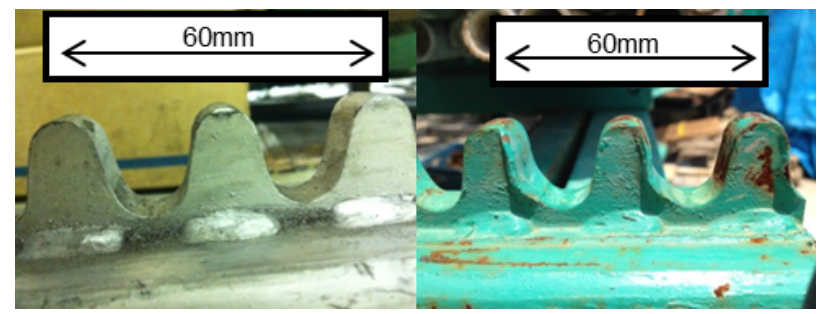

Fig.2 Rack rail (left: original right: worn).

To solve the problem, it should be one of effective ideas to change the power contribution ratio on each pinion gear by driving them individually in another method. However, appropriate condition has not been shown if front pinion and rear pinion gear were individually driven to reduce the stress applied onto rack teeth of rack rail.

The purpose of this study is to find the optimum power contribution ratio defined as the ratio of traction force applied onto the rack rail by front and rear pinion gear of the monorail used in this study. At first, relation between loading weight and applied stress was investigated when loading 
weight $\mathrm{M}_{\mathrm{b}}$ on the bogie was changed. To calculate the traction force, relationship between observed stress and the traction force applied to the rack tooth was previously prepared considering the beam theories. Power contribution ratio was estimated using the relationship in the experiment. The effect of the condition of power contribution ratio on the stress applied onto the rack rail was simulated using obtained relations. The optimum power contribution ratio of front pinion gear was defined as an effective designing parameter to reduce the stress applied onto the rack tooth. A reduction ratio determined with the ratio of maximum compression stress on the tooth considering power contribution ratio to that of conventional case was estimated when the optimum power contribution ratio was considered.

\section{EXPERIMENTAL AND SIMULATION METHOD}

\section{A. Experimental Condition}

Fig. 3 shows the appearance of the motor vehicle used in this study. The monorail was driven by a motor vehicle leading bogie on a rack rail.

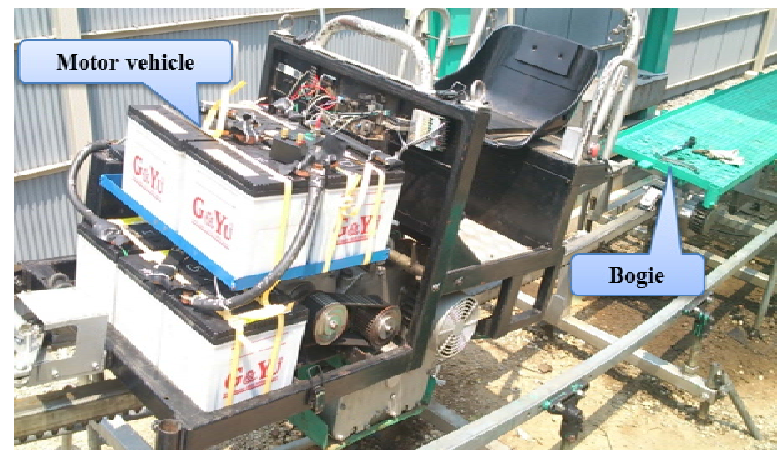

Fig.3 Motor vehicle used in this study.

For current study, electrical motor was utilized as the power source instead of reciprocal diesel engine which was for general applications. Table 1 shows vehicle specification of motor vehicle and bogie used in this study. To make the traction force on the rack rail, two pinion gears were jointed with the driving shaft rotated by the motor, as shown in Fig.4. The numbers of revolutions of the two pinion gears were inevitably synchronized by the center gear hidden in the gear box. The number of pins inserted in the front and rear gear was 11 , respectively.

Stable engagements were achieved by sub-wheels. The sub-wheels were freely traveled on the rack rail to support the dead weight of the driving vehicle at the counter locations of gears, respectively. If the gear swerved from right position gears and sub-wheel would hold the rack rail between them to avoid the jumping of the vehicle.

Due to the backlash between pinion gears and rack gear, positive pitching angle $\theta[\mathrm{deg}]$ was obligated to be observed. The h1 $[\mathrm{mm}]$ and $\mathrm{h} 2[\mathrm{~mm}]$ shown in the figure were defined as the distance between the root of tooth and contacting point of the pin to the rack tooth in front pinion gear, and that in rear pinion gear, respectively.

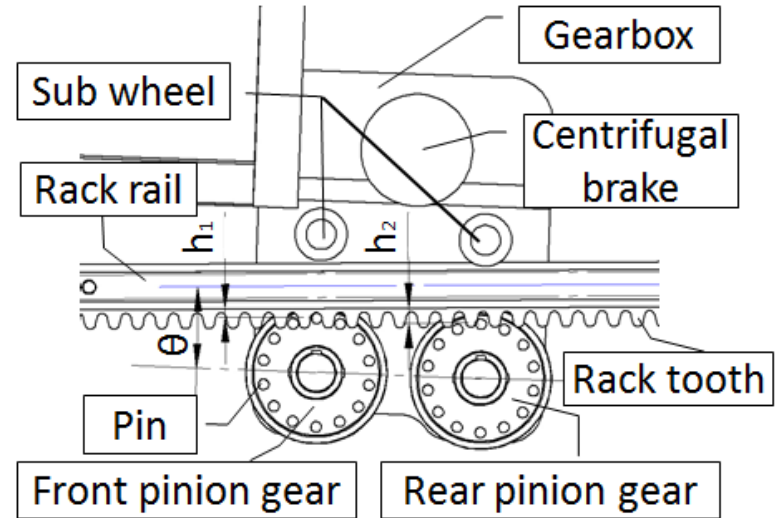

Fig.4 Layout of rack rail and pinion gears in driving unit.

Table 1 Vehicle Specification

\begin{tabular}{|c|c|c|}
\hline \multirow{2}{*}{ Table Head } & \multicolumn{2}{|c|}{ Table Column Head } \\
\cline { 2 - 3 } & Moter vehtcle DH700 & Bogle \\
\hline Length/Width & $1400 / 720 \mathrm{~mm}$ & $2000 / 720 \mathrm{~mm}$ \\
\hline Power & $22 \mathrm{~kW}$ & - \\
\hline Weight & $510 \mathrm{~kg}$ & $300 \mathrm{~kg}$ \\
\hline \multirow{2}{*}{ Brake } & \multicolumn{2}{|c|}{ Centrifugal brake } \\
\cline { 2 - 3 } & hand brake & - \\
\hline Battery & $96 \mathrm{~V} 52 \mathrm{Ah}$ & - \\
\hline
\end{tabular}

\section{B. Calculation Method of Traction Force Applied onto} Rack Tooth

To calculate the traction force, relationship between observed stress on the rack rail and the traction force applied onto the gear was previously prepared considering the beam theories. The normal stress at point A (Fig.5) was calculated by Eq.(1).

$$
\sigma_{\mathrm{g}}=-\frac{P \sin \theta_{\mathrm{p}}}{\mathrm{L}(\mathrm{y}) \mathrm{t}}+\frac{6 \mathrm{PL}(\mathrm{h}) \sin \theta_{\mathrm{p}}}{\mathrm{L}(\mathrm{y})^{2} \mathrm{t}}-\frac{6 \mathrm{P}(\mathrm{h}-y) \cos \theta_{\mathrm{p}}}{\mathrm{L}(\mathrm{y})^{2} \mathrm{t}}
$$

Here,

First term: compression stress generated by the load in Y- axial direction of the traction force. Second term: bending stress generated by $\mathrm{Y}$ axial direction load of the traction force. Third term: bending stress generated by the load in X-axial direction of the traction force. $\mathrm{P}$ : Traction force $[\mathrm{N}], \mathrm{y}$ : distance between the root of tooth and point $\mathrm{A}$ $[\mathrm{mm}], \mathrm{h}$ : distance between the root of tooth and contacting point of the pin to the rack tooth[mm], t: thickness of tooth $[\mathrm{mm}], \theta_{\mathrm{p}}$ : pressure angle of tooth. Width of rack tooth, $\mathrm{L}(\mathrm{y})$ was geometrically expressed as

$$
\mathrm{L}(\mathrm{y})=20.7-0.460 \mathrm{y}(5.56 \leqq \mathrm{y} \leqq 15.6 \mathrm{~mm})
$$

at $y[\mathrm{~mm}]$ from the root of tooth. Range of height $\mathrm{h}$ was 5.56 $\leqq \mathrm{h} \leqq 15.6 \mathrm{~mm}$. The pressure angle of the pin on the rack tooth $\theta \mathrm{p}$ was assumed to be $12.9^{\circ}$. 


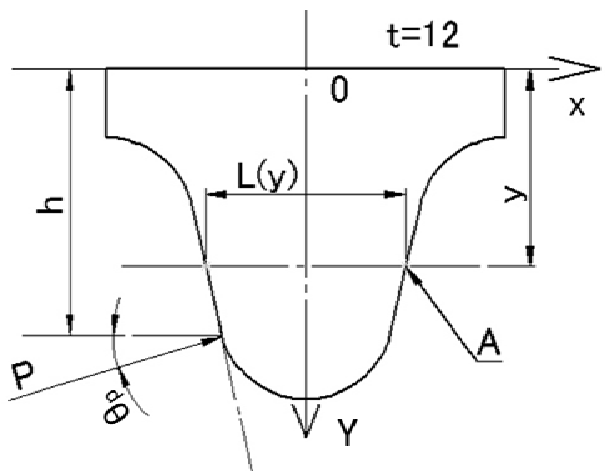

Fig.5 Structure view of rack tooth of rack rail.

\section{Estimation Method of Loading Weight Refereeing Observed Stress}

Relation between loading weight and applied stress was investigated when loading weight $\mathrm{M}_{\mathrm{b}}$ on the bogie was changed. Strain gage was attached to measure the change of stress applied onto the rack tooth when the monorail was driven on the rack rail of the test course with 45 degree of upward slope (Fig.6). The location of strain gage was $\mathrm{y}=5.56 \mathrm{~mm}$ as previously shown in Fig.5, where the equivalent von Mises stress on the surface of the tooth showed the maximum as confirmed by result of FEM simulations (Fig.7).

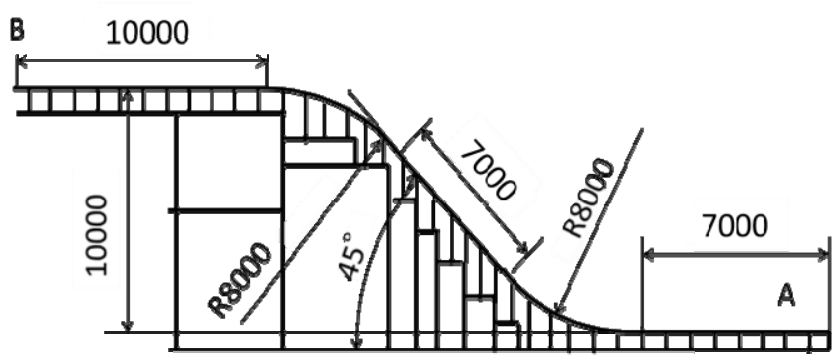

Fig.6 Schematic view of test course.

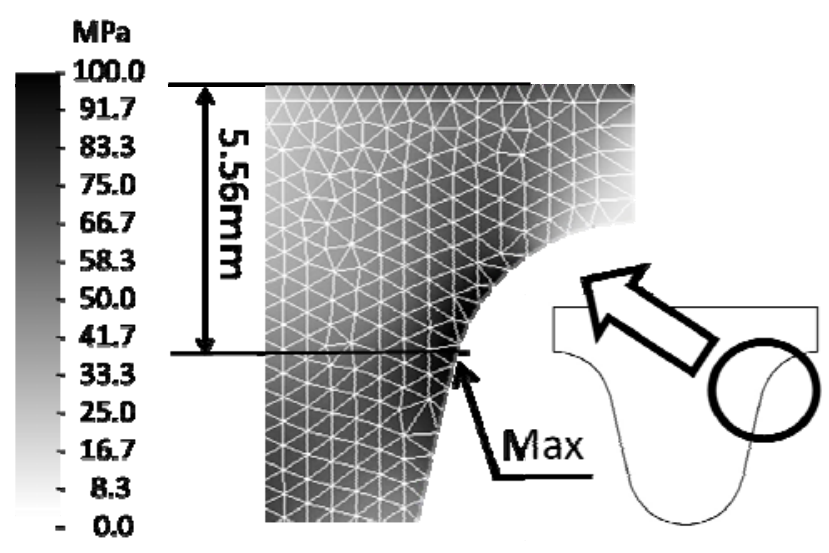

Fig.7 Example of FEM result of equivalent stress in tooth of rack rail.

\section{Detection of Engaged Point of Pin to Rack Tooth}

Pressure sensitive paper was attached onto rack tooth of rack rail to investigate the representative point of contacting pressure by the pin to the rack rail, because engagements of rack and pinion is important to simulate the stress [2].

\section{E. Definition of Power Contribution Ratio}

Power contribution ratio $(\alpha)$ was defined with traction forces as equation bellow Eq.(3), where it was considered that two pinion gears were rotated in the same revolution and vehicle velocity was constant.

$$
\begin{aligned}
& \alpha=\frac{\mathrm{vP}_{\text {front }}}{\mathrm{vP}_{\text {front }}+\mathrm{vP}_{\text {rear }}}=\frac{\mathrm{P}_{\text {front }}}{\mathrm{P}_{\text {total }}} \\
& \mathrm{P}_{\text {wotal }}=\mathrm{P}_{\text {hront }}+\mathrm{P}_{\text {neetr }} \\
& \mathrm{P}_{\mathrm{wowa}}=\mathrm{M}_{\mathrm{2}} \mathrm{g}\left(\sin \theta_{1}+\mu \cos \theta_{1}\right) \\
& M_{c}=M_{m}+M_{b}+M_{w}
\end{aligned}
$$

$\mathrm{M}_{\mathrm{m}}$ : Vehicle weight $(\mathrm{kg}) \mu$ : Driving resistance factor $(-)$

$\mathrm{M}_{\mathrm{b}}$ : Bogie weight $(\mathrm{kg}) \mathrm{g}$ : Acceleration of gravity $\left(\mathrm{m} / \mathrm{s}^{2}\right)$

$\mathrm{M}_{\mathrm{w}}$ : weight (kg) $\quad \theta_{1}$ : Tilt angle of rail( $\left.\mathrm{deg}\right)$

\section{RESULTS AND DISCUSSION}

\section{A. Traction Force and Maximum Compression Stress}

Fig.8 shows the variation of measured maximum compression stress applied onto the rack rail tooth with the change of the loading weight. It was found that magnitude of stress applied onto rack rail by the rear pinion gear was not depended on magnitude of loading weight, while that of front pinion gear was almost linearly increased by it.

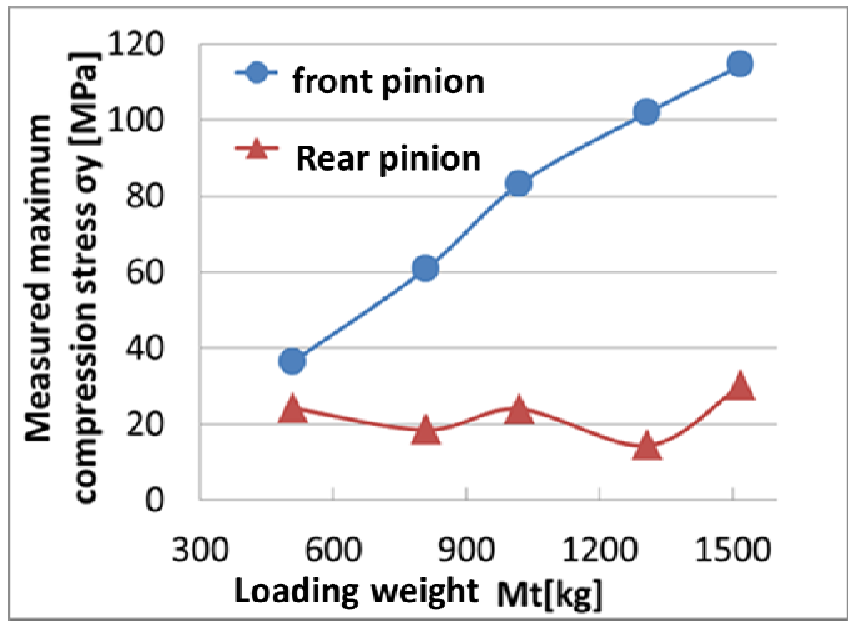

Fig. 8 Measured maximum compression stress $\sigma_{\mathrm{y}}$.

Fig.9 shows the difference of contact pressure distributions on rack teeth observed by the pressure sensitive papers and representative location of the 
contacting force was determined. The representative location of the contacting forces on front pinion gear was $\mathrm{h} 1=5.6 \mathrm{~mm}$ measured from the root of tooth, and that on rear pinion gear was $\mathrm{h} 2=7.0 \mathrm{~mm}$, respectively.

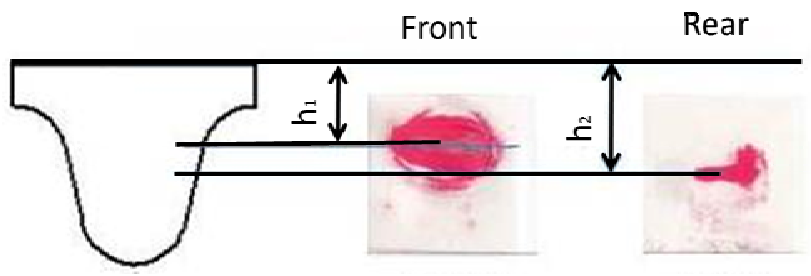

Fig. 9 Contact pressure distributions on rack teeth.

Fig.10 shows the linear relationships between simulated compression stress at $y=5.56 \mathrm{~mm}$ from the tooth root and traction force at each gear calculated by Eq.(1). In this simulation, contacting force for the traction was representatively applied at the point of $h 1$ and $h 2$, respectively. The sheared traction force on each gear was estimated by measuring the strain on the tooth of the monorail used in this study, here stress-strain relation and the obtained relationship between applied stress and traction force were utilized.

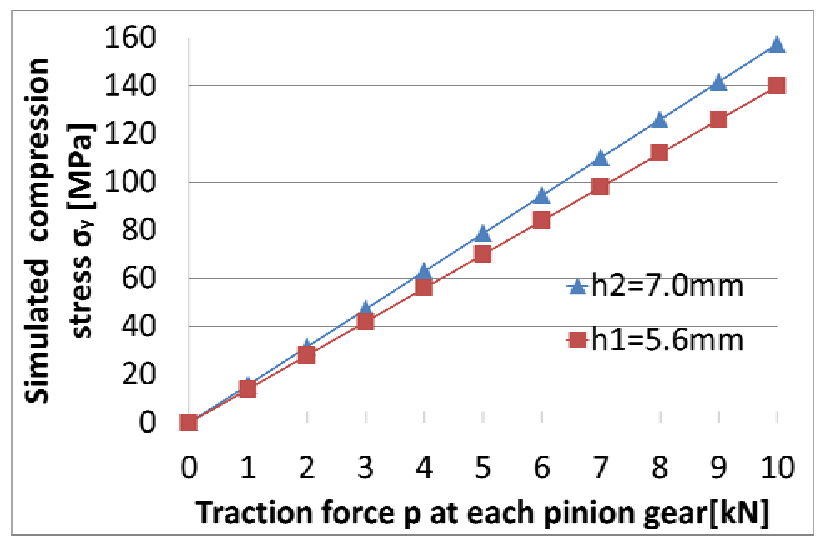

Fig.10 Relationships between simulated Compression stress and traction force.

\section{B. Power Contribution Ratio}

Fig.11 shows the change of each traction force and power contribution ratio when the total traction force was changed.

It was found that most of traction force was sheared by the front pinion gear not depending on magnitude of traction force, because the revolutions of the front and rear pinion gears was directly constraint due to the link system of the connection in the gear box of current monorail.

The power contribution ratio of front pinion gear was approximately $\alpha=0.6$ when relatively low traction force was applied onto the rack rail. On the other hand, when relatively large traction force was applied, power contribution ratio of front pinion gear was increased over $\alpha=0.8$ ( $\alpha=0.87$ in maximum).

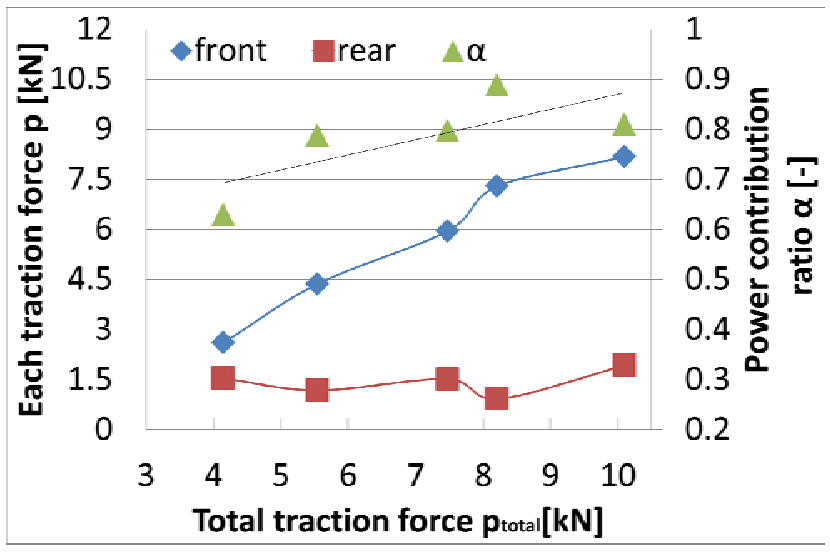

Fig.11 Change of each traction force and power contribution ratio.

\section{Optimum Power Contribution Ratio}

Fig.12 shows the change of simulated maximum compression stress $\sigma_{\mathrm{y}}$ applied onto the rack tooth when power contribution ratio was changed under the condition of total mass $\mathrm{Mt}=1520 \mathrm{~kg}$, where actual driving condition was considered. The simulation results showed that the maximum compression stress was depended on the power contribution ratio. In the case of low power contribution ratio of front pinion gear, location of the maximum compression stress was laid on the rack rail engaging with rear pinion gear. On the other hand, maximum compression stress was observed at rack tooth engaging with front pinion gear under the condition of high power contribution ratio of front pinion gear.

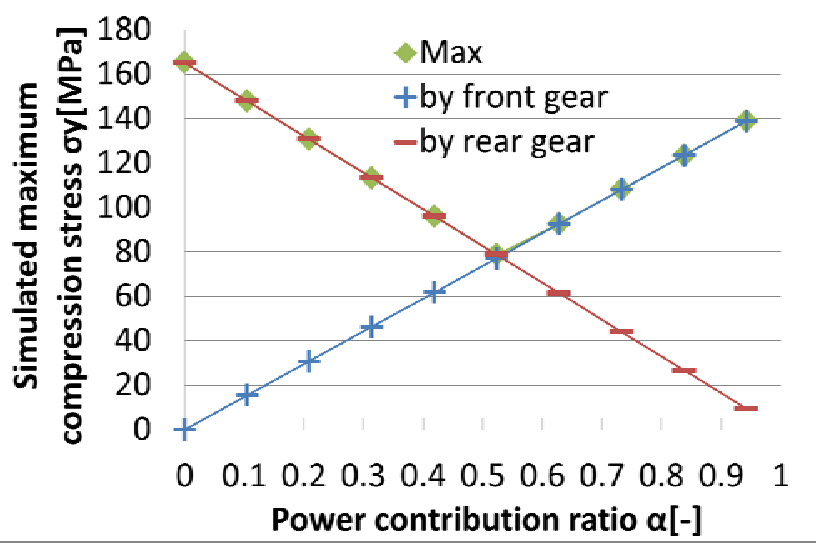

Fig.12 Relationships between maximum stress and power contribution ratio.

By the results, it was found that power contribution ratio was an effective designing parameter to reduce the stress applied onto the rack tooth to prevent the rapidly wear of rack tooth. The maximum compression stress applied onto the rack tooth was most effectively reduced approximately $35 \%$ by determining $\alpha=0.53$ of power contribution ratio, compared with that of conventional case under the condition of total mass $\mathrm{Mt}=1520 \mathrm{~kg}$. In this study "optimum power contribution ratio" was defined as the power contribution 
ratio where maximum compression stress applied onto the rack tooth was reduced in minimum.

Fig.13 shows the change of optimum power contribution ratio and simulated maximum compression stress when the total traction force was changed.

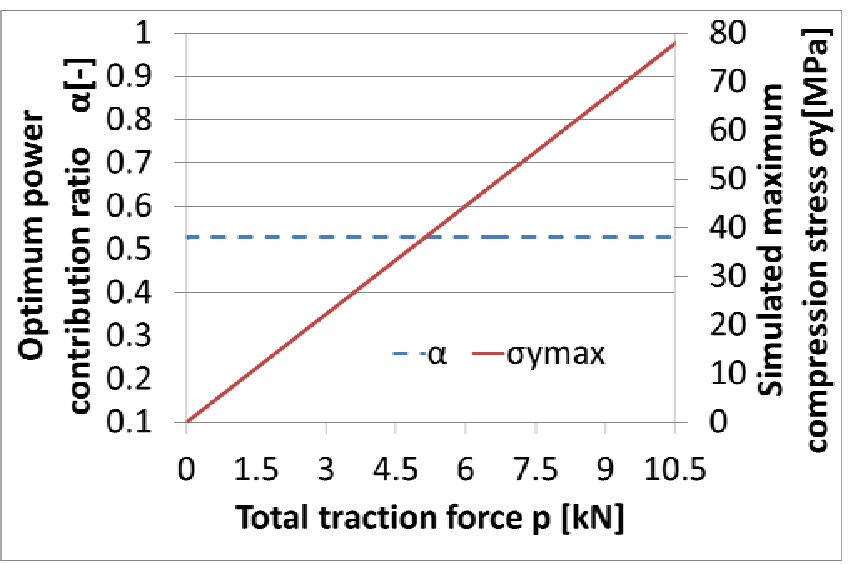

Fig.13 Optimum power contribution ratio and simulated maximum stress.

It was confirmed that optimal power contribution ratio was not depended on the magnitude of total traction force, while linear relation between the magnitude of total traction force and maximum stress applied onto rack tooth was observed by the simulation. Fig.14 shows the change of maximum compression stress under the condition of optimum power contribution ratio and its reduction ratio when the total traction force was changed, here the reduction ratio was defined as the ratio of maximum compression stress applied onto the tooth to that of conventional case.

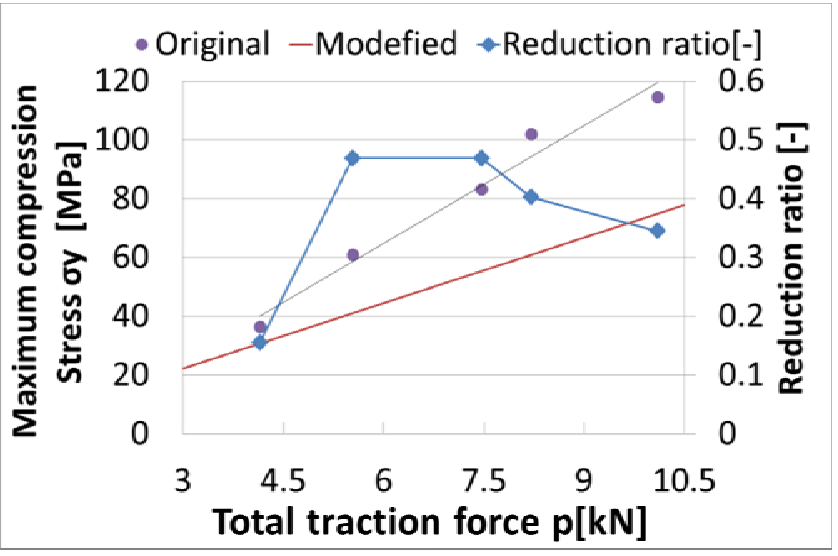

Fig.14 Relationships between maximum stress and traction force.
The maximum reduction with $47 \%$ in observed compression stress was obtained by determining optimum power contribution ratio under the condition of $5.54 \mathrm{kN}$ of total traction force.

\section{CONCLUSIONS}

- Most of traction force was sheared by the front pinion gear not depending on magnitude of traction force, because the number of revolutions of the front and rear pinion gears was directly constraint due to the link system of the connection in gear box of current monorail.

- The optimum power contribution ratio was $\alpha=0.53$ when the representative location of the contacting forces on front pinion gear was $\mathrm{h} 1=5.6 \mathrm{~mm}$ measured from the root of tooth, and that on rear pinion gear was $h 2=7.0 \mathrm{~mm}$, respectively.

- The maximum reduction with $47 \%$ in observed compression stress was obtained by determining optimum power contribution ratio under the condition of $5.54 \mathrm{kN}$ of total traction force.

\section{REFERENCES}

[1] Aidin PARSAKHOO, Seyed Ataollah HOSSEINI, Majid LOTFALIAN, and Hamid JALILVAND GUINGAND,"Soil loss and displacement by heaby equipment in forest road subgrading project" International Journal of Sediment Research 24 (2009) 227-230

[2] Sripati Sah, Robert X. Gao and Timothy Kurp,"Model-augmented methods for estimation of contact pressure distribution,"Journal of Manufacturing Systems 30, pp.223-233(2011) 